\title{
Sociedade, trabalho e sentido da vida: se fere nossa existência, seremos mais que resistência
}

\author{
Carta de Luci Praun ${ }^{1}$
}

Resumo: Este texto, que por iniciativa editorial foi desenvolvido em formato de carta, trata sobre processos de saúde-adoecimento abrigados sob a denominação transtornos mentais. A ênfase recai sobre os desdobramentos desses processos em tentativas ou óbitos por suicídio, cujas estatísticas mundiais e brasileiras têm se apresentado de forma ascendente. Busca-se, ao introduzir a temática e as estatísticas correspondentes, problematizar sobre as fronteiras entre a esfera da vida pessoal e a do trabalho e, de forma decorrentes, sobre o quanto esses episódios podem ser inseridos no âmbito da sociabilidade capitalista contemporânea e ao profundo processo de degradação do trabalho.

Palavras-chave: Capitalismo Contemporâneo; Suicídio; Processos de Saúde-adoecimento; Centralidade do Trabalho.

\footnotetext{
${ }^{1}$ Doutora em Sociologia pela Unicamp. Professora visitante da Universidade Federal do ABC. E-mail: lupraun@uol.com.br
} 
Santo André, 30 de setembro de 2018.

Marx, meu caro,

Há cerca de um mês, entre as correspondências que recebo diariamente, uma chamou-me especialmente a atenção. A pessoa escrevia em nome de um dos cursos da universidade onde atuo como docente. $\mathrm{O}$ tom era de pesar. Mais um jovem havia, conforme as palavras de quem redigiu a mensagem, "interromp[ido] sua própria trajetória".

Fiquei algum tempo lendo aquela curta mensagem. Recordei outras situações como aquela. Tem sido recorrente tomarmos conhecimento sobre tentativas de suicídios e, muitas vezes, sobre sua efetivação. Aquele não era, infelizmente, um caso isolado. A ocorrência de suicídios tem apresentado nos últimos anos, por uma multiplicidade e convergência de fatores, curva ascendente. Aquele caso, junto com tantos outros, sabemos, é apenas a ponta de um enorme iceberg.

Coloco-o, a seguir, a par de algumas estatísticas atuais. Após apresentá-las, gostaria de tecer algumas breves considerações sobre os processos de saúde-adoecimento relacionados ao trabalho, com destaque aos chamados transtornos mentais e suas repercussões no que se refere ao suicídio. Também pretendo, a título de abrir o diálogo sobre a questão, questionar sobre as fronteiras entre a esfera da vida pessoal e a do trabalho. Há muito sabemos o quanto essas fronteiras são esfumaçadas.

Saliento que não estou considerando, com essa afirmação, o trabalho invisível, conveniente ao capital, e não remunerado, desenvolvido cotidianamente por milhões de mulheres. Esse sequer é reconhecido como trabalho. A expressão trabalho socialmente conveniente tem sido utilizada por Marc Bessin (2016) em seus estudos sobre as práticas de cuidado, realizadas essencialmente no ambiente doméstico e marcadas por atributos naturalizados como femininos, vinculados às 
demandas familiares, característica que tende a operar no sentido de reforçar a invisibilidade social do trabalho, deslocando-o para o campo das "obrigações" familiares e, não raro, destituindo-o da necessidade de remuneração. Parece-me, a expressão, bastante adequada.

No momento em que te escrevo, apesar da persistência de uma suposta separação, por diferentes meios e formas, essas fronteiras entre a esfera pessoal e a do trabalho são praticamente inexistentes, mesmo nas situações clássicas, do trabalho exercido em horário préestabelecido e fora de casa. Muitos, atualmente, ergueram gabinetes de trabalho em casa.

Mas antes, vamos às informações prometidas. Os dados mundiais são sistematizados e consolidados pela Organização Mundial da Saúde (OMS) em base a diferentes fontes e indicam que ocorrem no mundo cerca de 800 mil mortes, anualmente, por suicídio. Há consenso sobre a parcialidade das informações, já que a coleta depende da preexistência de bancos de dados nacionais alimentados com regularidade a partir de diferentes órgãos públicos e privados. Muitos países, em geral os mais pobres, não possuem qualquer forma de coleta de dados epidemiológicos da população local, entre eles, sobre os casos relatados. Em outros, ainda que existam os sistemas de coleta, por estigmatização e/ou preconceito (em alguns países a prática é considerada ilegal), as ocorrências não são devidamente reconhecidas e classificadas (WHO, 2014, p. 9 e 16).

A OMS destaca que os suicídios ocorrem com maior frequência, se consideradas as diferentes regiões do mundo, entre homens e mulheres com 70 anos ou mais. No Brasil, as estatísticas para essa faixa etária também são mais elevadas se comparadas às demais isoladamente. Do ponto de vista geral, a relação, considerado o universo do estudo da OMS, é de 11,4 suicídios para cada 100 mil habitantes, com incidência diferenciada entre homens, com 15,0 por 100 mil, e mulheres, com 8,0 por $100 \mathrm{mil}$ (WHO, 2014).

Quando observados a partir de países selecionados, é possível destacar a incidência por gênero, raça, geração, indicadores 
socioeconômicos, entre outros recortes, e estabelecer correlações. Destaco, do relatório da OMS, a correlação observada entre maior incidência de suicídios em regiões com prevalência de renda média baixa e de renda baixa. Nessas regiões ocorrem mais da metade dos casos (415 mil). Chama também a atenção que seja o suicídio, quando observado em escala global, "a segunda causa principal de morte entre pessoas de 15 a 29 anos". O caso que relato no início desta carta é parte dessa estatística. A entidade destaca ainda que para "cada adulto que se suicidou, possivelmente, existem outros 20 que tentaram suicidar$\mathrm{se}^{\prime \prime 2}$ (2014, p. 9).

Estudos como o realizado por Christophe Dejours e Florence Bègue (2010) avançaram na identificação da correlação de parte crescente dessas ocorrências com as condições e situações de trabalho vivenciadas no atual estágio do capitalismo. Mas disso, tratarei adiante.

No Brasil, as estatísticas governamentais sustentam-se nas notificações, obrigatórias, enviadas por órgãos públicos e privados ao Ministério da Saúde por meio do Sistema de Informação de Agravos de Notificação - SINAN. Compõe a base para o levantamento estatístico oficial sobre casos de tentativa de suicídio e/ou de sua efetivação, as notificações categorizadas como "Violência interpessoal /Autoprovocada ${ }^{3 \prime \prime}$. Desse conjunto de notificações são isolados os casos de lesão autoprovocada e, no interior deste grupo, aqueles caracterizados como tentativa de suicídio/ óbito por suicídio.

Por aqui, conforme levantamento relativo ao período de 2011 a 2015, quando agrupadas as faixas que compreendem aqueles dos 10 aos 39 anos, encontramos mais de $70 \%$ dos casos de tentativa de suicídio. A incidência entre adolescentes e jovens é alta ${ }^{4}$.

\footnotetext{
2 Tradução livre do inglês.

3 "A violência autoprovocada compreende autoagressões, automutilações e tentativas de suicídios" entre homens e mulheres que não tenha como resultado o óbito. (2016, p. 8)

${ }^{4}$ 0-9 (0,37\%); 10-19 (21,95\%); 20-29 (27,38\%); 30-39 (23,15\%); 40-49 (15,51\%); 50-59 (7,84\%); 60 ou mais $(3,8 \%)$, conforme dados publicados pelo Ministério da Saúde (BRASIL, 2017).
} 
Quando considerados os óbitos por suicídio, a maior taxa observada está, tal como os indicadores mundiais, entre aqueles e aquelas com 70 anos ou mais (8,9 por 100 mil habitantes), sobretudo entre os homens (com incidência mais de cinco vezes superior que entre as mulheres). Altíssima é a taxa observada entre os povos indígenas, de 15,2/100 mil habitantes e com concentração de 44,8\% entre adolescentes e jovens de 10 a 19 anos, fenômeno que sem dúvida tem sido objeto de diversos pesquisadores dedicados ao estudo das comunidades indígenas no Brasil. Nas demais faixas, para o período de 2011 a 2015, os dados são os seguintes: faixa de 20-29 anos, com 6,8/ 100 mil; 30-39, com 7,4; 40-49, com 7,9; 50-59, 8,0; 60-69, 7,7 (BRASIL, 2017, p. 9).

Ao serem considerados os indicadores brasileiros entre 2007-2016, observa-se também um crescimento de $18 \%$ dos óbitos por suicídios. Em 2016, 31 casos por dia foram registrados. Considerando os casos notificados, o número implica em aumento de 2,3\% se comparados aos dados consolidados no ano anterior, 2015 (CANCIAN, 2018).

Enfim, vi-me naquele final de tarde, quando a correspondência que menciono no início dessa carta chegou, mais uma vez diante de um misto de tristeza, incômodo e indignação. Meus pensamentos se aproximaram daqueles por você anotados, em 1846, quando de suas leituras das Memórias de Jacques Peuchet ${ }^{5}$. Foi inevitável questionar sobre que sociedade é essa, capaz de causar esvaziamento do sentido de viver e sofrimento tão profundos a ponto de fazer com que um contingente crescente homens e mulheres, muitos ainda jovens, não consiga vislumbrar outra saída que não a de "interromper sua própria trajetória".

O fenômeno, evidentemente, tem sido cada vez mais discutido. Mas a abordagem, ainda que estabeleça regularmente a correlação entre crescimento das estatísticas de suicídio com a incidência de casos de depressão, por exemplo, ainda trata essas ocorrências sem ancorá-

${ }^{5}$ Ver MARX (2006). 
las devidamente à sociabilidade tecida pelo capitalismo em sua atual fase. As estimativas da Organização Mundial da Saúde (2018) indicam que a depressão atinge atualmente, no mundo, "mais de 300 milhões de pessoas, de todas as idades".

Permita-me, meu caro, retomar, a partir dos dados de hoje, algumas questões salientadas por suas anotações de 1846, feitas a partir dos trechos das Memórias de Jacques Peuchet. Nelas são descritos quatro casos de suicídio, entre os quais três envolvendo mulheres. As histórias relatadas por Peuchet revelam, uma a uma, como as estruturas de opressão incidem de forma particular sobre as mulheres.

As informações atuais obtidas pelo governo brasileiro não incluem relatos dessa natureza, mas fornecem indicadores importantes. Por um lado, tal como indicam as observações de Peuchet, as mortes por suicídio continuam atingindo majoritariamente os homens, conforme mencionado anteriormente. Por outro lado, 69\% das tentativas de suicídio, para o mesmo período, foram levadas à cabo por mulheres. Sobre a faixa de idade, as ocorrências entre mulheres são maiores entre os 50 e 59 anos, com 3,8 casos para cada 100 mil habitantes (BRASIL, 2017).

Os dados atuais, portanto, reafirmam o que sugerem suas anotações de 1845. Gênero é categoria de análise essencial também para compreensão do fenômeno das tentativas e mortes por suicídio. Mas veja que, apesar dos papéis sociais delimitados, da divisão sexual do trabalho, tal como a definem Helena Hirata (2002) e Claudia Nogueira (2011), Meneghel et al. (2012, p. 1986) observam que gênero é "fator de vulnerabilidade ao suicídio tanto para homens como para mulheres", na medida em que "as normas de gênero", apesar de "na maioria das situações" se apresentarem "desfavoráveis às mulheres" tendem, ainda que por meios diferenciados, a não poupar também os homens, "mesmo quando ocupam posição de destaque e poder".

Ao longo da investigação que realizaram, as pesquisadoras puderam por um lado identificar como a impossibilidade de corresponder a códigos de conduta e papéis sociais estabelecidos constitui elemento importante para a compreensão do desenlace das 
histórias de vida dessas pessoas. Por outro lado, também puderam iluminar nas histórias as intersecções entre gênero e trabalho. O recorte de gênero transparece nas histórias de privação, de violência, de uma vida dedicada ao cuidar dos outros, ao cuidar da família, ainda bastante comum entre as mulheres, sobretudo entre aquelas cujo labor vai marcando seus corpos. Revela-se também na ruptura com a vida fora de casa, muitas vezes imposta pela velhice, pela doença incapacitante, pela aposentadoria, pelo desemprego, pelas repercussões que essas condições provocam diante do papel atribuído ao homem, de chefe e provedor da família em confronto com as possibilidades de sua realização (MENEGHEL et al., 2012).

Há nessas histórias de vida, tal como destacam as autoras, "sofrimento ligado ao trabalho", expresso no temor de não ter como se sustentar, "no sentimento de inutilidade causado pela aposentadoria, na exigência de trabalhar até a morte e no próprio fato de morrer 'ajoelhado' ${ }^{\prime 6}[. .$.$] , assujeitado" (MENEGHEL et al., 2012, p.1989).$

Seja por sua ausência, fruto da aposentadoria, do desemprego, ou pelo adoecimento que interrompe a atividade profissional, ou pela pressão cotidiana dentro dos locais de trabalho, ou ainda pelo esvaziamento da casa, com a partida dos filhos e filhas, pela perda do companheiro de uma vida inteira (de quem devo cuidar agora!?, perguntam-se muitas mulheres cuja vida estruturou-se em torno do cuidar da família), de muitas dessas histórias emerge o trabalho, mesmo aquele invisibilizado e não remunerado.

Mas esse é um dado, meu caro Marx, que pouco aparece nas estatísticas. O mesmo sistema de notificações que permite identificar ocorrências de violência autoprovocada, tentativas e óbitos por suicídio, o SINAN, também possibilita, se estabelecido o nexo pelo profissional que atende o trabalhador ou trabalhadora, e preenchidos os dados adequadamente, a identificação da motivação da ocorrência. Mas a correlação com o trabalho mantém-se praticamente inexistente.

${ }^{6}$ Em dois dos casos relatados, de morte por enforcamento, os trabalhadores são encontrados já sem vida, de joelhos. 
Mais uma vez te apresento os dados. Conforme as estatísticas brasileiras, para o período de 2011 a 2016, no que se refere às lesões autoprovocadas, $0,8 \%$ constam como relacionadas ao trabalho desenvolvido por mulheres. Para os homens o índice é de 1,1\%. Quando pinçadas as tentativas de suicídio, 299 notificações indicam nexo laboral, o que corresponde a $0,6 \%$ para mulheres e $0,7 \%$ para homens (BRASIL, 2017).

No Brasil, na ficha de notificação utilizada para ocorrências de Violência Interpessoal /Autoprovocada, entre as possibilidades explicitadas como motivação, "trabalho" não consta sequer como alternativa ${ }^{7}$, em confronto com sua centralidade econômica, social, cultural e psíquica na vida cotidiana de milhões de homens e mulheres.

Dejours e Bègue (2010, p. 15), ao abordarem sobre as notificações na França, apontam situação semelhante.

Não se sabe, ao certo, quantos suicídios relacionados ao trabalho ocorrem a cada ano na França. Essa falta de conhecimento decorre da inexistência, nas pesquisas epidemiológicas, sobre suicídio, de rubrica que permita detectar eventos que poderiam estar relacionados ao trabalho ou com a situação profissional.

Há, é preciso afirmar, evidente subnotificação não somente no que diz respeito às ocorrências específicas tratadas até aqui, sintoma expressivo da "degradação do conjunto do tecido humano e social do trabalho" (DEJOURS; BĖGUE, 2010), mas também frente ao conjunto de adoecimentos relacionados ao trabalho, com ênfase para os casos de transtorno mental, que não necessariamente evoluem para situações de lesões autoprovocadas, tentativas ou óbitos por suicídio.

\footnotetext{
${ }^{7}$ São essas as alternativas estimuladas presentes na ficha de notificação utilizada para ocorrência de Violência interpessoal /Autoprovocada: 01-Sexismo; 02-Homofobia/ Lesbofobia/Bifobia/Transfobia; 03-Racismo; 04-Intolerância religiosa; 05-Xenofobia; 06-Conflito geracional; 07-Situação de rua; 08-Deficiência. Consta ainda: 09-Outros, com espaço para que se especifique a motivação; 88-Não se aplica; 99 - Ignorado.
} 
As notificações relativas a doenças relacionadas ao trabalho, entre as quais aquelas classificadas como transtornos mentais, apesar de crescentes, estão longe de refletir a realidade. Pesquisas como as desenvolvidas por Cordeiro et al. (2016), Seligmann-Silva (2011); Praun (2016a, 2016b), entre outros estudos, apontam nesse sentido.

As razões para a subnotificação são variadas. Entram em jogo tanto os limites (não por acaso) das fichas de notificação, já mencionados, como a burla deliberada, praticada tanto por empresas como órgãos públicos, voltada a favorecer interesses empresariais em detrimento da saúde e direitos dos trabalhadores.

Mas vale também destacar, meu caro, a persistência, sobretudo no campo das ciências biológicas e da saúde, de ideologias sobre um corpo humano apartado do mundo que o cerca, reduzido à sua dimensão biológica. Quando predominam concepções dessa natureza, o que é social e coletivo é reduzido ao natural e individual. O trabalho, elemento estruturante da vida de milhões de homens e mulheres, simplesmente desaparece.

As vozes insurgentes por certo existem, inclusive no campo da medicina. Uma delas é a da médica e pesquisadora, naturalizada mexicana, Asa Cristina Laurell. Para Laurell (1982, p. 12), o "processo biológico humano é social. É social na medida em que não é possível focalizar a normalidade biológica do homem à margem do momento histórico".

Relembro aqui uma passagem de um de seus textos de 1844 . Eles chegaram às minhas mãos sob o título de Manuscritos Econômicos e Filosóficos ${ }^{8}$. Em uma passagem, você afirma:

O indivíduo é o ser social. Sua manifestação de vida - mesmo que ela também não apareça de forma imediata de uma manifestação comunitária de vida, realizada simultaneamente com os outros é, por isso, uma externação e confirmação da vida social. A vida individual e a vida genérica do homem não são diversas, por mais

\footnotetext{
${ }^{8}$ Editado pela Boitempo em 2010.
} 
que também - e isso necessariamente - o modo de existência a vida individual seja um modo mais particular ou mais universal da vida genérica, ou quanto mais a vida genérica seja uma vida individual mais particular ou universal (2010, p.107)

Laurell (1982), empenhada em desvelar os processos de saúdeadoecimento, destaca que conhecê-los implica, necessariamente, em se deslocar o indivíduo em direção à coletividade. Esse movimento de ir ao coletivo revela o objeto de estudo e sua essência social. O corpo e os processos a ele inerentes são, portanto, resultado da relação e inserção no mundo. Como compreendê-lo sem considerar o trabalho?!

Meu pensamento, nesse momento é novamente tomado por aquele jovem, do início da carta. Sei pouco sobre ele, o garoto que "interrompeu sua própria trajetória". Sei, entretanto, que não foi o único. E quando faço o movimento de deslocá-lo para a coletividade, recordo das palavras escritas por Paulo Arantes (2011), ao comentar um dos livros publicados por Dejours. Na busca por identificar as singularidades do trabalho na atual fase do capitalismo, assim afirma Arantes (2011, p. 38):

Voltando à tentativa de identificação desse "trabalho" (para assim retirar-lhe as aspas), lembrando mais uma vez que ele só seria plenamente reconhecido à medida em que se cristaliza a percepção de que o novo mundo do trabalho moldado pela racionalidade neoliberal dominante, se transforma num imenso amplo de experimentação e difusão da crueldade social, descontada, é claro, toda a cosmética clean da acumulação flexível, por David Harvey, entre outros, como se sabe.

Essa racionalidade, a qual se refere Arantes, extrapola os muros dos tradicionais locais de trabalho. Entre os muros das empresas privadas e órgãos públicos passamos a conviver, cada vez mais, com sistemas de metas que, conforme ressalta Vincent Gaulejac (2007, p. 101), “... dão o sentimento a cada assalariado de ser tratado como os outros". Esse sentimento, ressalta o autor, induz cada um a pensar, e às 
vezes até a exaltar, a objetividade dos critérios de avaliação. As métricas e a meritocracia estão em alta. Elas tecem a falsa sensação de que cada um, enfim, está sendo valorizado por seu desempenho. A eficácia desse processo assenta-se em diversos e articulados mecanismos, que operam nos ambientes de trabalho sim, mas são tecidos e emaranhados nas diferentes instâncias da vida social.

Danièle Linhart (2000), ao tratar das mudanças no mundo do trabalho deu destaque ao que denominou como individualização, capaz de impulsionar a competição e favorecer à constituição de um ambiente de trabalho que pressiona, de forma difusa, para a adesão às regras do jogo. Aderir, por sua vez, implica trabalhar “... a si mesmo para se tornar mais produtivo", de forma a "... tornar a empresa - que é a entidade de referência - mais produtiva" (Dartdot \& Laval, 2016, p. 343).

A exigência de que encarnemos cada vez mais a concorrência do mercado tem ao seu favor o conjunto de mudanças que degradam e precarizam as relações de trabalho, conforme há muito vem sinalizando Ricardo Antunes (2000). Mas o ar que respiramos, diante do confronto com imposições que ferem a nossa existência, tende a impregnar-se cada vez mais de um sentimento difuso de mal-estar. "No fim", ressalta Dejours (2012, p. 28-29), contrariando o sentido da vida humana, que se realiza mediada pela relação com o outro, com o mundo, "cada um se encontra só, no meio da multidão, em um ambiente humano e social com características de hostilidade".

Pesquisadoras como Selma Venco e Margarida Barreto observam como esse "contexto de instabilidade configura-se como campo fértil para a instalação de patologias do medo, cujas características de angústia frente às incertezas são equivalentes às vivenciadas pela situação de desemprego" (2010, p.5). Concordando com elas, destaco o quanto, este ambiente hostil tem sido particularmente perverso com a juventude trabalhadora, desafiada a encarar um mundo onde a precariedade dos vínculos, a frágil e instável inserção no mercado de trabalho, soma-se a exigências constantes e progressivas características da racionalidade concorrencial neoliberal. 
Os velhos fios da opressão e da exploração, ainda que renovados, seguem cumprindo a função de fixar a complexa trama da sociabilidade capitalista. A resposta para esse conjunto de inquietações, sabemos, está não somente nas formas de exploração postas em movimento pelo capitalismo, mas também na ordem social que as sustenta. Persistem, preciso dizer, nas suas diferentes formas, as resistências. Mas nossa resistência ainda não logrou transformar as estruturas da sociedade. Ainda temos um mundo a ganhar. Um mundo em que o excedente criado pelo trabalho possa ser convertido em tempo socialmente livre, em trabalho emancipado (MARX, 2011).

As marcas do trabalho estão, pois, nos corpos, evidenciando nossa humanidade. As do trabalho que explora e violenta o corpo, que esvazia a vida de sentido, também. Ambas, cada vez mais, devem, de forma socialmente conveniente tornar-se invisíveis. Visibilizá-las implica em desvelar a profunda mercantilização e descartabilidade da vida humana. Implica, portanto, em resistir. Em evidenciar a necessidade de projetarmos uma sociedade e sociabilidade para além do capital.

Em tempo. Vivenciamos nesse último período, em diferentes partes do mundo, o crescimento de grupos da ultradireita. No Brasil, parte importante desses grupos, no momento em que escrevo essa carta, aglutina-se em torno de uma candidatura às eleições presidenciais, em curso. Em contrapartida, uma heterogênea, mas vigorosa e interessante movimentação feminista vem tomando as ruas. Entre as frases que sedimentam a unidade dos diferentes grupos, uma em especial: "Se fere minha existência, serei resistência!". Penso que deveríamos colocala no plural. Se fere nossa existência, seremos resistência! E acrescer: seremos a transformação!

Receba meu fraterno abraço,

Luci Praun 


\section{Referências bibliográficas}

ANTUNES, Ricardo. Os Sentidos do Trabalho. Ensaio sobre a afirmação e a negação do trabalho. 3ํo ed. São Paulo: Boitempo, 2000.

ANTUNES, Ricardo; PRAUN, Luci. A Sociedade dos Adoecimentos no Trabalho. Serviço Social \& Sociedade, São Paulo, v.123, Jul./Set. 2015. Disponível em http://www.scielo.br/pdf/sssoc/n123/01016628-sssoc-123-0407.pdf Acesso em outubro de 2018.

ARANTES, Paulo. Sale Boulot: Uma janela sobre o mais colossal trabalho sujo da história. Tempo Social, São Paulo, v. 23, n. 1, Jun. 2011. Disponível em http://www.scielo.br/pdf/ts/v23n1/ v23n1a03 Acesso em outubro de 2018.

BESSIN, Marc. "Política da Presença: As questões temporais e sexuadas do cuidado". In: ABREU, Alice Rangel de Paiva; HIRATA, Helena; LOMBARDI, Maria Rosa. Gênero e Trabalho no Brasil e na França: perspectivas interseccionais. São Paulo: Boitempo, 2016.

CANCIAN, Natália. Brasil registra 11 mil casos de suicídio por ano, diz Ministério da Saúde. Folha de São Paulo, Cotidiano, 20 Set. 2018. Disponível em https://www1.folha.uol.com.br/ cotidiano/2018/09/brasil-registra-11-mil-casos-de-suicidio-porano-diz-ministerio-da-saude.shtml Acesso em outubro de 2018. BRASIL. Boletim Epidemiológico. Secretaria de Vigilância em Saúde - Ministério da Saúde. Volume 48, º 30, 2017.

CORDEIRO, Técia Maria Santos Carneiro e et al . Notificações de transtornos mentais relacionados ao trabalho entre trabalhadores na Bahia: estudo descritivo, 2007-2012. Epidemiologia e Serviços de Saúde, Brasília, v. 25, n. 2, Jun. 2016 . Disponível em $<$ http://www.scielo.br/scielo.php?script=sci_arttext\&pid=S2237- 
96222016000200363\&lng=en\&nrm=iso $>$. Acesso em outubro de 2018.

DARDOT, Pierre; LAVAL, Christian. A nova razão do mundo: ensaio sobre a sociedade neoliberal. São Paulo: Boitempo, 2016.

DEJOURS, Christophe. Sexualidade e Trabalho. Trabalho Vivo, Tomo I. Brasília: Paralelo 15, 2012.

GAULEJAC, Vincent de. Gestão como doença social. Ideologia, poder gerencialista e fragmentação social. Aparecida, SP: Ideias e Letras, 2007.

HIRATA, Helena. Nova Divisão Sexual do Trabalho. Um olhar voltado para a empresa e a sociedade. São Paulo: Boitempo, 2002.

LINHART, Danièle. O indivíduo no centro da modernização das empresas: um reconhecimento esperado, mas perigoso. Trabalho E Educação. Revista do NETE, Belo Horizonte, v. 7, 2000.

LAURELL, Asa Cristina. La salud-enfermidad como proceso social. Cuadernos Médico Sociales, México, № 19, Enero de 1982. Disponível em: http://capacitasalud.com/biblioteca/wp-content/ uploads/2016/02/Cuadernos-Medico-Sociales-19.pdf Acesso em outubro de 2018.

MARX, Karl. Sobre o suicídio. São Paulo: Boitempo, 2006.

. Manuscritos Econômicos e Filosóficos. São Paulo: Boitempo, 2010.

. Grundrisse. São Paulo: Boitempo, 2011.

\begin{tabular}{l|l}
\hline 158 & Sociedade, trabalho e sentido da vida:...
\end{tabular} 
MENEGHEL, Stela Nazareth; GUTIERREZ, Denise M. D.; SILVA, Raimunda M. da; HESLER, Lilian Zielke; CECCON, Roger Flores. Suicídio de idosos sob uma perspectiva de gênero. Ciência \& Saúde Coletiva, Rio de Janeiro, v. 17, n. 8, p. 1983-1992, agosto de 2012. Disponível em http:// www.scielo.br/scielo.php?script=sci_arttext\&pid=S1413$81232012000800009 \& \operatorname{lng}=\mathrm{en} \& n \mathrm{~nm}=\mathrm{iso}>$. Acesso em outubro de 2018.

NOGUEIRA, Claudia Mazzei. O Trabalho Duplicado - A divisão sexual no trabalho e na reprodução: um estudo das trabalhadoras do telemarketing. São Paulo: Expressão Popular, 2011.

OMS. Folha Informativa. Março, 2018. Disponível em: https://www. paho.org/bra/index.php?option=com_content\&view $=$ article\& $\mathrm{id}=5635$ :folha-informativa-depressao\&Itemid $=822$ Acesso em outubro de 2018.

PRAUN, Luci. Reestruturação Produtiva, Saúde e Degradação do Trabalho. Campinas, SP: Papel Social, 2016a.

PRAUN, Luci. A solidão dos trabalhadores: sociabilidade contemporânea e degradação do trabalho. Cadernos de Psicologia Social do Trabalho, v. 19, n. 2, Dez. 2016b. Disponível em: http:// www.revistas.usp.br/cpst/article/view/140593/135552 Acesso em outubro de 2018.

SELIGMANN-SILVA, Edith. Trabalho e Desgaste Mental. O direito de ser dono de si mesmo. São Paulo: Cortez, 2011.

VENCO, S.; BARRETO, M. O sentido social do suicídio no trabalho. REA - Revista Espaço Acadêmico, v. 9, n. 108, p. 1-8, 2010. Disponível em http://www.assediomoral.org/IMG/pdf/Selma_ 
Venco_e_Margarida_Barreto_-_O_sentido_social_do_suicidio_ no_trabalho_1_.pdf. Acesso em outubro de 2018.

WORLD HEALTH ORGANIZATION - WHO. Preventing suicide: a global imperative [Internet]. Geneva: World Health Organization; 2014, [cited 2018 Sep 25]. 88p. Disponível em http://apps. who.int/iris/bitstream/10665/131056/1/9789241564779_eng. pdf?ua=1\&ua=1 Acesso em outubro de 2018.

\begin{tabular}{l|l}
\hline 160 & Sociedade, trabalho e sentido da vida:...
\end{tabular} 